\title{
EVALUATION OF RHOMBIC THREE DIMENSIONAL PLATE IN TREATMENT OF MANDIBULAR SUBCONDYLAR FRACTURES IN ADULT PATIENTS FROM ALEXANDRIA
}

\author{
Gaafar N. El Halawani ${ }^{I} M . S c$, Sherif S. Ayad ${ }^{2} P h D$, Sameh A. Darwish ${ }^{2} P h D$, \\ Ragab S. Hassan'2PhD
}

\begin{abstract}
INTRODUCTION: Open reduction-internal fixation (ORIF) of extracapsular condylar fracture is necessary when there is a displacement of $10-45^{\circ}$, or a shortening of the ramus by more than $2 \mathrm{~mm}$. The two miniplates is considered the gold standard in fixation of condylar fractures. however, it needs a certain size of the proximal segment restricting its use to low condylar neck fracture. Recently a 3D rhombic plate was introduced, which can be used with high condylar neck fracture, while still providing good anatomical positioning and stability.

OBJECTIVES: To evaluate both clinically and radiographically the three dimensional rhombic plate compared with the two miniplates in the fixation of mandibular subcondylar fractures.

MATERIALS AND METHODS: This prospective clinical study was performed on 20 patients with extracapsular condyle fractures. Patients were divided into 2 groups. Group I was treated with the three dimensional rhombic plate and group II was treated with two miniplates.

RESULTS:There was a significant difference in the maximal mouth opening between the two groups at 3 months postoperatively in favor of the study group, however there was no significant difference in mandibular mobility throughout the follow up period.20\% of patients from group (I) and $30 \%$ of patients from group (II) had lateral deviation in mouth opening on the first week. This was absent in both groups on the third week postoperatively. The difference between the two groups was not statistically significant one week. The mean bone density in the study group was statistically significantly higher than the control group at 3 and 6 months postoperatively.

CONCLUSIONS: The application of the Rhombic plate for the stable osteosynthesis of condylar fractures ensures satisfactory treatment results, both from the clinical and the radiological points of view.

KEYWORDS: Subcondylar fracture, Rhombic plate, Three dimensional plates.
\end{abstract}

1- Assistant lecturer at Oral and Maxillofacial Surgery Department, Faculty of Dentistry, Alexandria University.

2- Professor of Oral and Maxillofacial Surgery, Department of Oral and Maxillofacial Surgery, Faculty of Dentistry, Alexandria University.

\section{INTRODUCTION}

Fractures of the mandibular condyles are common and account for 25 to $45 \%$ of all mandibular fractures (1).

Management of mandibular condylar fractures remains an ongoing matter of controversy in maxillofacial surgery. This controversy is reflected in the wide variety of opinions and proposed treatment modalities offered in the literature (2).

For decades, closed reduction has been the preferred treatment because it is easier, less invasive and the results are comparable, with no surgical complications. However, closed reduction may comprise varying periods of intermaxillary fixation (IMF) (0 to 6 weeks) followed by aggressive physiotherapy $(2,3)$. In addition, long-term complications such as pain, arthritis, malocclusion, deviation of the mandible on opening and closing movements, temporomandibular joint (TMJ) dysfunction, facial asymmetry and reduced posterior facial height as well as ankylosis may occur in patients with condylar injuries treated in a closed manner (4).

If there is a displacement of $10-45^{\circ}$ or a shortening of the ramus by more than $2 \mathrm{~mm}$, surgical management seems to be preferred. Open reduction-internal fixation (ORIF) allows anatomic repositioning and immediate functional movements of the jaw, as well as reconstructing the vertical ramus height $(5,6)$.

Today, open reduction and rigid internal fixation can be achieved with a variety of different plating systems using intraoral or extraoral approaches such as preauricular, retromandibular and endaural approach. However, condylar fractures are difficult to access through the intraoral approach and need endoscope assistance (7-10).

Clinical and biomechanical studies reported the 2 miniplates to be the most reliable procedure for fixation of condylar fractures. These neutralize tension and pressure forces best and produce greater stability. However, two miniplates require a certain size of the proximal condyle fragment and thus are applicable mainly in cases involving low fractures $(11,12)$.

In an attempt to provide smaller plates while maintaining good fixation and stabilization along the fracture line, a three dimensional delta plate was introduced. The design of this plate allows for treatment of even high condylar neck fractures. The plate's delta shape can handle changing loads in three dimensions, with the highest tensile strain occurring at the anterior and lateral surfaces and the highest compressive strains on the posterior surface as well as torque strains (13-15).

Despite this, biomechanical studies showed that the delta plate was inferior to the two miniplates regarding medial to lateral load, lateral to medial load and anterior to posterior load and was only superior with the posterior to anterior load (13).

Recently, a rhombic three dimensional plate was introduced as a modification to the delta plate, changing the three sided delta shape of the delta plate into a four sided rhombic design to improve stability and biomechanical properties of the plate. The non- locking rhombic plate has two characteristic gliding holes to compress the fracture through screw adjustments, which accelerate bone healing. 
Moreover, during reduction, the 2 gliding holes allow for more freedom and final adjustment of the fragments when the screws are already placed but not tightened. Then tightening the screws achieves a better approximation with better interdigitation of the spiky fracture ends (16).

The new rhombic plate for condylar fractures has 3 main advantages: i) neutralization of changing strains that affects the condylar region; ii) the additional stabilization provided by a compression miniplate; and iii) a small osteosynthesis plate (16).

The objective of this study was to evaluate both clinically and radiographically the use of three dimensional rhombic plate compared to the use of two conventional miniplates in the fixation of extracapsular mandibular subcondylar fractures.

\section{MATERIALS AND METHODS}

This study was conducted as a prospective comparative clinical study on twenty patients selected from the Oral and Maxillofacial Surgery Department, Faculty of Dentistry, Alexandria University. All patients signed an informed consent before undergoing the surgery. The study was ethically cleared by the institutional ethical committee.

To qualify for surgery, patients were required to fulfill the following criteria: 1- Medically fit patients free from relevant conditions contraindicating surgery. 2- Patients with age range 30-40 years old. 3-Patients suffering from displaced extracapsular mandibular subcondylar fracture indicated for open reduction presented within two weeks from trauma. Patients with relevant bone diseases or infected fracture site were excluded from the study.

\section{Materials:}

In this study, 2 types of plates were used for fixation of mandibular subcondylar fracture: 1- The 3-dimensional rhombic plate (KLS Martin, Tuttlingen, Germany), which is manufactured of pure titanium (grade 2) of $1.0 \mathrm{~mm}$ thickness and secured with 5 screws of $2.0 \mathrm{~mm}$ head diameter. Also the plate has a unique feature of two gliding holes. 2-Two standard 4 or 5-holes titanium miniplates (KLS Martin, Tuttlingen, Germany) of $1.0 \mathrm{~mm}$ thickness secured with 4 self-tapping screws of $2.0 \mathrm{~mm}$ head diameter.

\section{Methods:}

\section{A) Pre-operative Phase:}

For all cases thorough history taking, clinical and radiographic examination were performed.

All patients were subjected to full clinical examination by inspection and palpation of the fracture sites both extraorally and intra-orally to detect the presence of edema, ecchymosis, soft tissue laceration, hemorrhage, site of fracture, dentition, derangement of occlusion, areas of tenderness, step deformities, mobility of fractured segments.

Radiographic examination was accomplished for all patients at the time of presentation. Axial, coronal, 3D reconstruction computerized tomography (CT) was taken for all patients.

\section{B) Operative Phase:}

Patients were divided into 2 equal groups, the study group was treated with Rhombic three dimensional plate (KLS Martin, Tuttlingen, Germany), while the control group was treated with two standard miniplates (KLS Martin, Tuttlingen, Germany).
The surgery was carried out under general anesthesia with nasal intubation. Intermaxillary fixation (IMF) was done to provide proper occlusion before plate fixation. In order to expose the fracture, a retromandibular approach was made. The incision was made $2 \mathrm{~cm}$ posterior to the posterior border of the ramus of the mandible. After incision, the parotid gland was separated from the sternocleidomastoid muscle and retracted superiorly. Subperiosteal dissection with stripping the masseter muscle off of the ramus was then performed to expose the fracture site.

After the localization of the fracture, the proximal fragment is reduced to the correct anatomical position using bone clamp.

In the study group, the rhombic 3D plate was curved to adapt to the condylar anatomy. The holes were than drilled and the plate fixed in place using 5 screws with $2 \mathrm{~mm}$ head diameter and $7 \mathrm{~mm}$ in length. (Figure1)

In the control group, the two miniplates were curved to adapt to the condylar anatomy. The first plate was placed parallel to the posterior border of the ramus, while the second plate was placed parallel to the anterior border of the condylar process along the sigmoid notch. Holes were drilled and 4 screws with $2 \mathrm{~mm}$ head diameter and $7 \mathrm{~mm}$ in length were used to fix each miniplate (Figure 2)
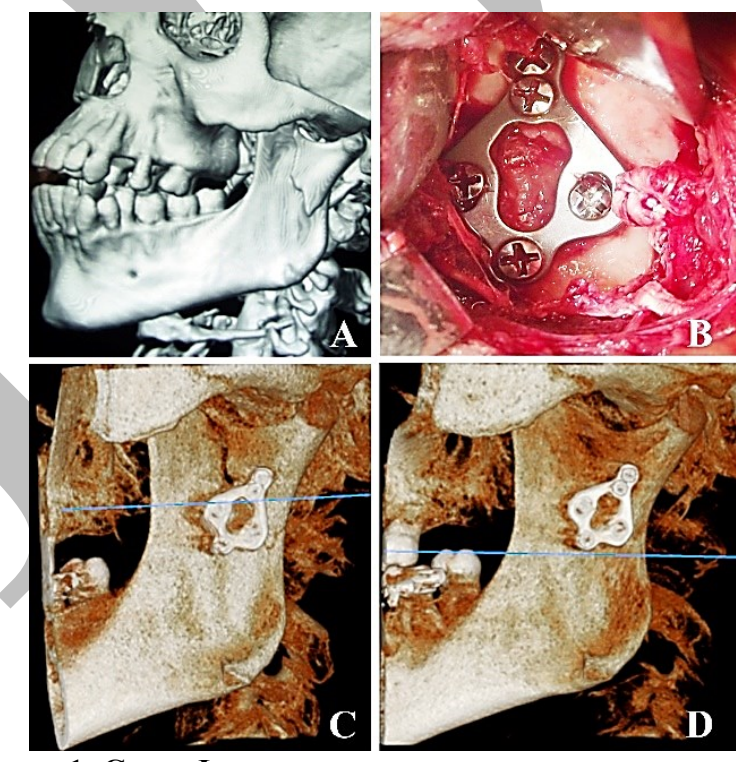

Figure 1: Group I

a: Preoperative computed tomography

b: Fixation using Rhombic 3D plate

c: $\mathrm{CBCT}$ immediate postoperative

d: CBCT at 6 months

After checking the correct reduction of the fracture and the stability of the internal fixation, the IMF was removed and the wound was closed in layers using polyglygolic polylactic 3-0 suture material (Vicryl, Ethicon, Cornelia, GA, USA) for deep layers and 4-0 polypropylene suture material (Prolene, Ethicon, Cornelia, GA, USA) for skin layer (Pterygomasseteric sling, platysma, subcutaneous tissue and skin).

\section{C) Postoperative Phase:}

Antibiotic schedule was prescribed post-operatively for 5 days, Amoxicillin/Clavulanate potasium 1 gm IV twice daily, (Augmentin, GlaxoSmithKline, Brentford, London). In addition to anti-inflammatory drug, Diclofenac sodium 75 mg IV (Cataflam, Novartis, Basel, Switzerland). All 
patients were advised to stick to postoperative care instructions to prevent postoperative complications. Dressing change was done by nursing staff on daily bases. Sutures were removed after 5 to 7 days.
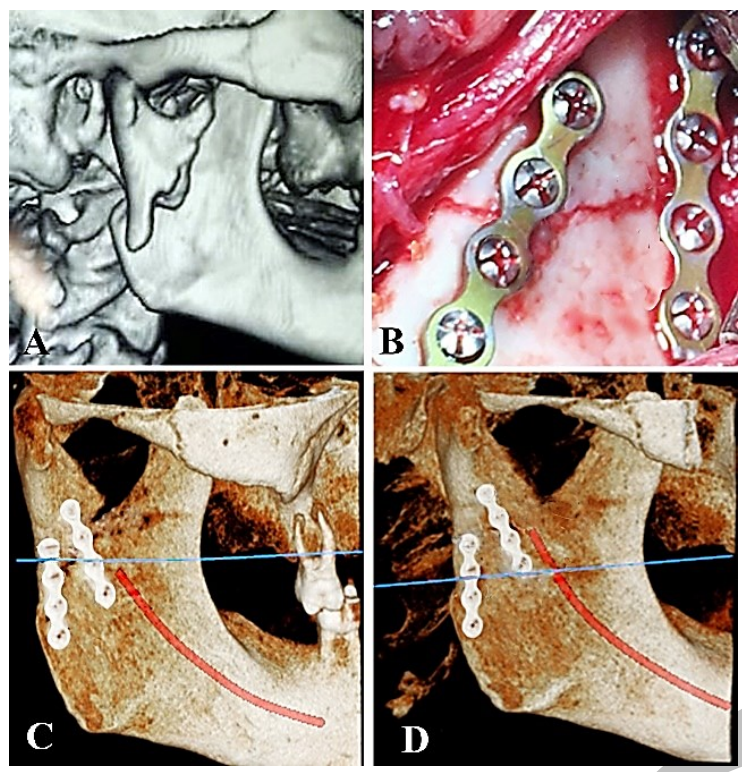

Figure 2: Group II

a: Preoperative computed tomography (Group II)

b: Fixation using 2 miniplates

c: $\mathrm{CBCT}$ immediate postoperative

d: $\mathrm{CBCT}$ at 6 months

\section{D) Follow-up Phase:}

Clinical follow-ups were carried out in all patients after 1 week, 3 weeks, 3 months and 6 months. The follow-ups comprised an analysis of the occlusion, the movement of the mandible in all three planes, lateral deviation in mouth opening, surgical wound for any signs of infection and any signs of facial nerve injury.

Radiographic studies were carried out using cone beam computed tomography (CBCT) immediately postoperative to check proper reduction and at immediate postoperative, 3 and 6 months to detect any cases of nonunion, plate fracture, loosening of plate and screws and for measuring the bone density in fracture line to check for healing and stability of the fixation method. Bone density was measured in the vicinity of the fracture line using the CBCT software. Six readings were taken each time and then the average was calculated to determine the mean bone density. Measurement was done in Hounsfield unitusing the BlueSky Plan software (Blue Sky Bio, Grayslake, IL, USA).

\section{STATISTICAL ANALYSIS:}

Statistical Package of Social Sciences (version 24.0; SPSS, Chicago, IL) was used to analyze the data.

Regarding the maximal mouth opening, lateral and protrusive excursive movements and the lateral deviation on mouth opening, the statistically analysis was done using the student $\mathrm{T}$ test.

Concerning the radiodensitometric measurements and the percent change in bone density. The statistical analysis was done using student t-test and Mann Whitney test respectively.

\section{RESULTS}

\section{Clinical evaluation}

This study included twenty patients with ages ranging from 30 to 40 years with an average of 35 years. 10 males were assigned to the study group, while 8 males and 2 females were assigned to the control group.

All patients were presented with unilateral subcondylar fractures. 15 patients were presented with right subcondyar fractures and 5 patients showed left subcondylar fractures. In 13 patients the subcondylar fracture was associated with contralateral parasymphyseal fractures, 6 patients showed contralateral body fracture and only one patient had an isolated subcondyalr fracture.

Regarding the intraoperative experience, the application of the rhombic 3D plate was easier and required minimal manipulation to the soft tissue compared to the 2 miniplates protocol.

None of the patients in either of the groups had nonunion, plate fracture, loosening of plate and screws, infection of the surgical wound or facial nerve injury within the follow up period and all patients had satisfactory occlusion throughout the study period.

Regarding the maximal mouth opening, there was no statistically significant difference between the two groups at 1 week, 3 weeks and 6 months. However, there was a significant difference between the two groups at 3 months in favor of the study group (Table 1, Figure 3). The lateral and protrusive excursive movements and the lateral deviation on mouth opening showed no significant difference between the two groups within the follow up period (Figure 4 and 5).

Table (1): Comparison between the two studied groups according to maximal mouth opening

\begin{tabular}{|l|c|c|c|}
\hline $\begin{array}{c}\text { Maximal mouth } \\
\text { opening }\end{array}$ & $\begin{array}{c}\text { Study } \\
(\mathbf{n}=\mathbf{1 0})\end{array}$ & $\begin{array}{c}\text { Control } \\
(\mathbf{n}=\mathbf{1 0})\end{array}$ & $\mathbf{p}$ \\
\hline 1 week & $18.0-30.0$ & $15.0-26.0$ & \\
Min. - Max. & $22.9 \pm 4.53$ & $20.4 \pm 3.75$ & 0.196 \\
Mean \pm SD. & 22.0 & 20.0 & \\
Median & $20.0-36.0$ & $18.0-35.0$ & \\
\hline 3 weeks & $28.5 \pm 5.52$ & $24.1 \pm 6.06$ & 0.107 \\
Min. - Max. & 30.0 & 21.5 & \\
Mean \pm SD. & $30.0-40.0$ & $25.0-40.0$ & \\
Median & $35.1 \pm 3.63$ & $29.7 \pm 5.62$ & $0.020^{*}$ \\
\hline $3^{\text {rd month }}$ & 35.0 & 27.5 & \\
Min. - Max. & & & \\
Mean \pm SD. & $35.0-40.0$ & $30.0-40.0$ & \\
Median & $38.4 \pm 2.01$ & $36.0 \pm 3.43$ & 0.072 \\
\hline $\mathbf{6}^{\text {th }}$ month & 39.5 & 36.0 & \\
Min. - Max. & & \\
Mean \pm SD. & & \\
Median & & & \\
\hline
\end{tabular}

p: $p$ values for Student t-test for comparing between the two studied groups

*: Statistically significant at $\mathrm{p} \leq 0.05$

\section{Radiographic evaluation}

Concerning the radiodensitometric measurements, the bone density in the study group was significant higher than the control group at 3 and 6 months (Table 2, Figure 6). The percent change in bone density from immediate postoperative to 3 months, immediate postoperative to 6 months and from 3 to 6 months also proved to be significantly higher in the study group showing faster bone healing in the study group (Table 3 ). 


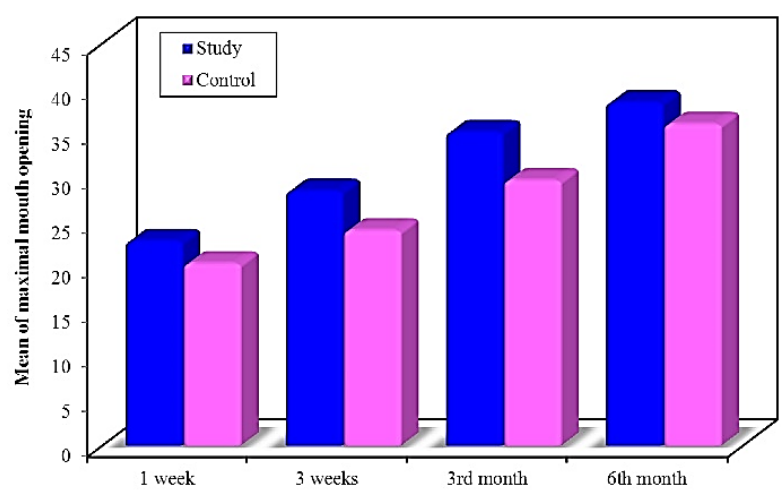

Figure 3: Comparison between the two studied groups according to maximal mouth opening

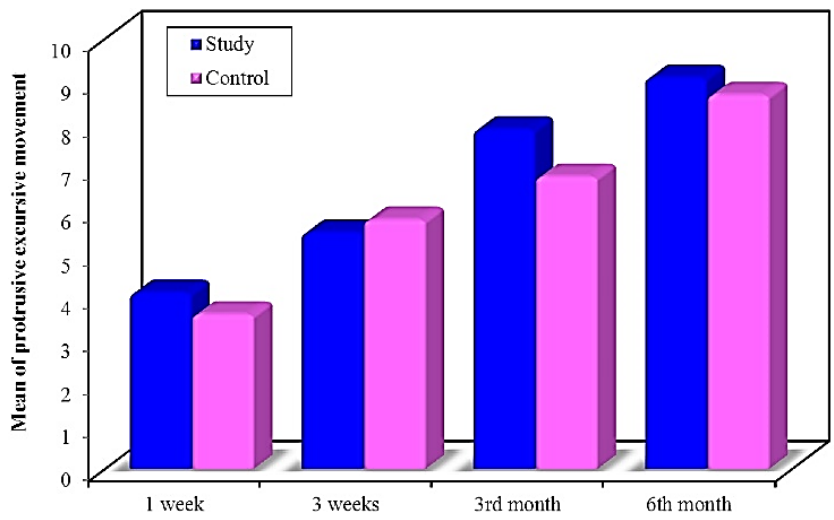

Figure 4: Comparison between the two studied groups according to protrusive excursive movement

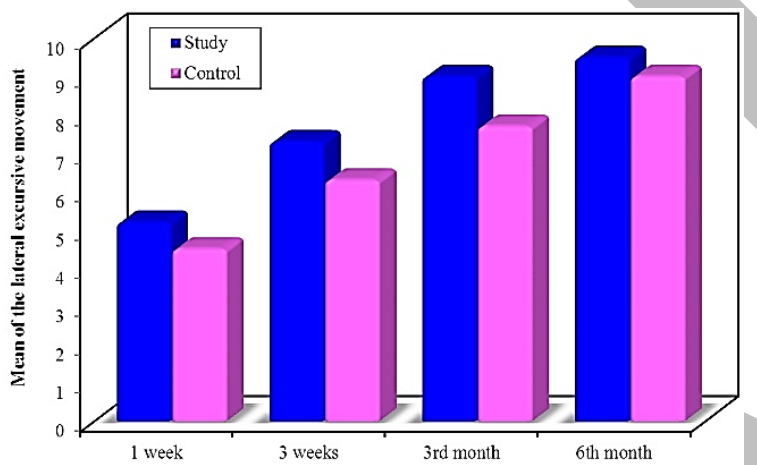

Figure 5: Comparison between the two studied groups according to the lateral excursive movement

\section{DISCUSSION}

In this study, clinical and radiographic outcomes were evaluated in both groups over a 6-months follow up period postoperatively. None of the patients in either of the groups had non-union, plate fracture, or loosening of plate and screws within the follow up period.

Sikora et al (17), in their clinical eyaluation of Delta plates reported no plate breakage. The same result was obtained by Haim et al (13) in their research on the biomechanics of Delta plates by their application in 40 porcine mandibles, as well as by Lauer et al. (14) in a 1year-long observation of 16 patients with all in all 19 Delta plates. Similar data were presented by Anirudhan et al (15). However, Sikora et al (17), after applying the Delta plate, observed a loosening of the retaining screws in $21 \%$ of the cases. This caused a minor displacement of the fragments in some cases and also a decrease of the mandibular ramus height in others, however, did not entail any significant disturbances in the fracture healing process. Lauer et al (14) also observed a loosening of the retaining screws in $21 \%$ of the cases, whereas Anirudhan et al (15) did not observe this complication in any of the nine cases that they studied.

Table (2): Comparison between the two studied groups according to bone density

\begin{tabular}{|l|c|c|c|}
\hline \multicolumn{1}{|c|}{ Bone Density } & $\begin{array}{c}\text { Study } \\
(\mathbf{n = 1 0})\end{array}$ & $\begin{array}{c}\text { Control } \\
(\mathbf{n = 1 0 )}\end{array}$ & $\mathbf{p}$ \\
\hline Immediately post- & & & \\
operative & & & \\
Min. - Max. & $480.6-570.4$ & $450.6-$ & \\
& 563.0 & \\
Mean \pm SD. & $523.9 \pm 33.31$ & $515.53 \pm$ & 0.614 \\
Median & 522.25 & 39.0 & \\
\hline $3^{\text {rd } \text { month }}$ & & 517.71 & \\
Min. - Max. & $855.9-925.3$ & $655.34-$ & \\
& $898.79 \pm$ & 870.44 & \\
Mean \pm SD. & 21.99 & $772.72 \pm$ & $<0.001^{*}$ \\
Median & 901.06 & 788.01 & \\
\hline $6^{\text {th }}$ month & $935.86-$ & $750.33-$ & \\
Min. - Max. & 1087.65 & 922.66 & \\
& $1020.45 \pm$ & $837.26 \pm$ & $<0.001^{*}$ \\
Mean \pm SD. & 47.10 & 55.25 & \\
Median & 1017.10 & 843.24 & \\
\hline
\end{tabular}

$\mathrm{p}$ : $\mathrm{p}$ values for Student $\mathrm{t}$-test for comparing between the two studied groups

*: Statistically significant at $\mathrm{p} \leq 0.05$

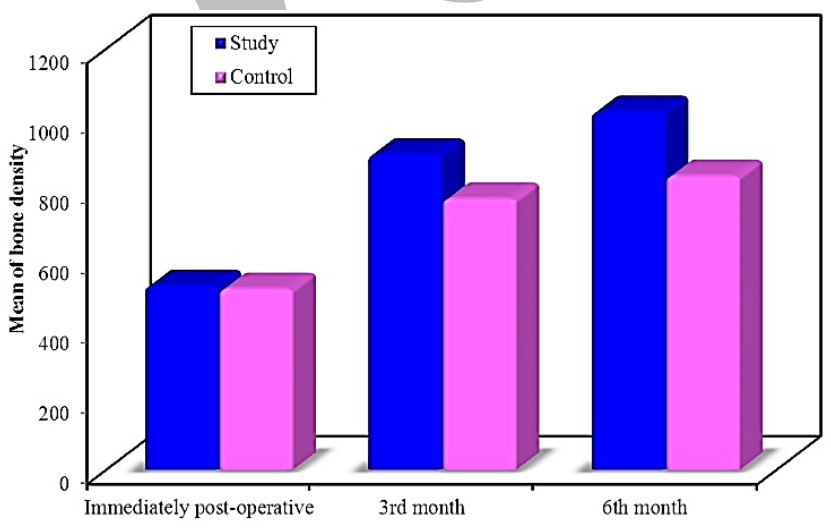

Figure 6: Comparison between the two studied groups according to bone density

Regarding facial nerve injury, none of the patients in our study showed any signs of facial nerve injury throughout the follow up period. However, Sikora et al (17) in their study diagnosed $7 \%$ of the patients during the postoperative period with a partial paresis of the facial nerve; in each of these cases, the correct function of the facial nerve returned spontaneously 3 months after the surgery. The observed disorders of the facial nerve function can probably be ascribed to the pressure on the tissue caused by the hooks used to visualize the operating area.

This opinion concerning the cause of the temporary postoperative paresis of the facial nerve is shared by other authors who applied the transparotid approach. Hou et al. (18), based on a comparative analysis of the complications after the retromandibular and transparotid approach, revealed that in a group of patients operated on by a retromandibular approach, the percentage of transient paresis of the cranial nerve VII amounted to a little over 
$13 \%$, while none of the patients operated on by a transparotid approach had this complication.

Table (3): Comparison between the two studied groups according to $\%$ change of bone density

\begin{tabular}{|l|c|c|c|}
\hline \multicolumn{1}{|c|}{ Bone Density } & $\begin{array}{c}\text { Study } \\
(\mathbf{n}=\mathbf{1 0})\end{array}$ & $\begin{array}{c}\text { Control } \\
(\mathbf{n}=\mathbf{1 0})\end{array}$ & $\mathbf{p}$ \\
\hline \% Change & & & \\
(Immediately - & & & \\
3months) & & & \\
Min. - Max. & $60.5-86.17$ & $24.71-75.46$ & \\
Mean \pm SD. & $72.03 \pm 8.60$ & $50.24 \pm 14.55$ & $0.001^{*}$ \\
Median & 73.79 & 52.15 & \\
\hline \% Change & & & \\
(Immediately - & & & \\
6months) & $76.68-111.44$ & $47.15-89.94$ & \\
Min. - Max. & $95.15 \pm 9.07$ & $62.95 \pm 12.87$ & $<0.001^{*}$ \\
Mean \pm SD. & 94.33 & 61.14 & \\
Median & & & \\
\hline \% Change (3months - & & & \\
6months) & $9.34-18.82$ & $1.96-19.83$ & \\
Min. - Max. & $13.5 \pm 3.18$ & $8.76 \pm 5.44$ & $0.019^{*}$ \\
Mean \pm SD. & 13.52 & 8.13 & \\
Median & & & \\
\hline
\end{tabular}

$\mathrm{p}$ : $\mathrm{p}$ values for Mann Whitney test for comparing between the two studied groups

*: Statistically significant at $\mathrm{p} \leq 0.05$

Croce et al. (19), on the other hand, in their research concerning the application of the transparotid approach, stated the occurrence of a temporary paresis of the facial nerve in as many as $27 \%$ of the patients, while Ellis et al (20), conducting research in the sixth week after open reduction and stable osteosynthesis of condylar fractures, observed this complication in $17.2 \%$ of the patients. In all cases, the correct function of the facial nerve returned spontaneously 6 months after the surgery.

Although there was a difference in the maximal mouth opening between the 2 groups at 3 months which can be attributed to the better fracture stability offered by the rhombic plate, after the conclusion of the treatment (i.e., 6 months after the surgery) all the patients showed an average range of mouth opening of $35 \mathrm{~mm}(30-40 \mathrm{~mm})$, average protrusive movement of $8.5 \mathrm{~mm}$ and an average laterotusion movement of $8.5 \mathrm{~mm}$ with no difference between the two groups.

Similar results were achieved by Lauer et al. (14) with the delta plate over 6 weeks after the surgery. The patients in their study presented with correct mandible mobility in all directions, with an average mandibular opening of $41 \mathrm{~mm}$, an average protrusion movement of $5 \mathrm{~mm}$, and an average laterotrusion movement of $6 \mathrm{~mm}$. Similar results concerning the restoration of the correct mandible mobility are presented also by Choi et al (21), Sandler (22) and Zrounba et al (23).

The results of the present study had shown that $20 \%$ of patients from group (I) and 30\% of patients from group (II) had lateral deviation on mouth opening on the first week postoperatively, this may be attributed to lateral pterygoid muscle affection due to trauma. However, this was absent in both groups on the third week postoperatively. The difference between the two groups was not satistically significant. Hidding et al (24) and You et al (25) also reported a $10 \%$ incidence of lateral deviation with open reduction of the condyle in general. Moreover, Lauer et al
(14) observed a slight lateral deviation on mouth opening to the fractured side in 7 of the 16 patients.

The difference in mean bone density and also the percent change in bone density between the two groups can be attributed to the better fracture stability and hence the faster bone healing offered by the 3D Rhombic plates during the healing period. This may be due to the ability of the three dimensional design of the plate to neutralize compressive, tensile and torsional strains.

Lauer et al. (16), in their biomechanical study on different plate designs including the delta plate and the two miniplates found that rigid internal fixation with double miniplates showed the best stability in all directions except posterior to anterior. In this direction, the delta plate resisted the highest loads. In the three other directions, the delta plate was second best with data similar to double miniplates but lower in magnitude.

Although this still needs to be tested biomechanically, the radiographic results of this study suggests that the modification of the 3 sided triangular pattern in the delta plate to a 4 sided rhombus form in the rhombus plate together with the effect of compression provided by the gliding holes provides us with a plate with higher stability then the 2 miniplates.

\section{CONCLUSIONS}

In conclusion, the application of the three dimensional Rhombic plate for the stable osteosynthesis of condylar fractures ensures fully satisfactory treatment results, both from the clinical and radiological points of view.

\section{CONFLICT OF INTEREST}

The authors declare that they have no conflicts of interest.

\section{REFERENCES}

1. Gassner R, TuliT, Hachl O, Rudisch A, Ulmer H. Craniomaxillofacial trauma: a 10-year review of 9543 cases with 21067 injuries. J Craniomaxillofac Surg.2003; 31: 51-61.

2. Kommers SC, van den Bergh B, Forouzanfar T. Quality of life after open versus closed treatment for mandibular condyle fractures: a review of literature. J Craniomaxillofac Surg 2013; 41: 221-5.

3. Danda AK, Muthusekhar MR, Narayanan V, Baig MF, Siddareddi A. Open versus closed treatment of unilateral subcondylar and condylar neck fractures: a prospective, randomized clinical study. J Oral Maxillofac Surg. 2010; 68:1238-41.

4. Shiju M, Rastogi S, Gupta P, Kukreja S, Thomas R, Bhugra $\mathrm{AK}$, et al. Fractures of the mandibular condyle - Open versus closed - A treatment dilemma. J Craniomaxillofac Surg. 2015; 43: 448-51.

5. Schneider M, Erasmus F, Gerlach KL, Kuhlisch E, Loukota RA, Rasse M, et al. Open reduction and internal fixation versus closed treatment and mandibulomaxillary fixation of fractures of the mandibular condylar process: a randomized, prospective, multicenter study with special evaluation of fracture level. Br J Oral Maxillofac Surg. 2008; 66: 253744.

6. Hakim SG, Wolf M, Wendlandt R, Kimmerle H, Sieg P, Jacobsen HC. Comparative biomechanical study on three miniplates osteosynthesis systems for stabilization of low condylar fractures of the mandible. Br J Oral Maxillofac Surg. 2014; 52: 317-22. 
7. Ebenezer V, Ranalingam B. Comparison of approaches for the rigid fixation ofsubcondylar fractures. J Maxillofac Oral Surg 2011;10: 38-44.

8. Ducic Y. Endoscopic treatment of subcondylar fractures. Laryngoscope 2008; 118: 1164-7.

9. Ellis E III, Kellman RM, Vural E. Subcondylar fractures. Facial Plast Surg Clin North Am 2012; 20: 365-82.

10. Patil RS, Gudi SS. Management of subcondylar fracture through intraoral approach with rigid internal fixation. J Maxillofac Oral Surg 2011; 10: 209-15.

11. Lauer G, Haim D, Proff P, Ritcher G, Pardel W, Fanghanel J Et al. Plate osteosynthesis of the mandibular condyle. Ann Anat. 2007; 189: 412-7.

12. Frerich B, Seemann R, Wagner A. Locking versus non locking miniplate osteosynthesis of mandibular fracturesPreliminary results. J Craniomaxillofac Surg. 2006; 34: 113-6.

13. Haim D, Müller A, Leonhardt H, Nowak A, Richter G, Lauer G. Biomechanical study of the Delta plate and the Tri Lock Delta condyle trauma plate. J Oral Maxillofac Surg. 2011; 69: 2619-25.

14. Lauer G, Pradel W, Schneider M, Eckelt U. A new 3dimensional plate for transoral endoscopic-assisted osteosynthesis of condylar neck fractures. J Oral Maxillofac Surg. 2007; 65:964-71.

15. Anirudhan A, Khalam SA, Zachariah RK. Evaluation of clinical use of indigenously developed delta plate in management of subcondylar fracture. Clin Pract. 2013; 3:74-6.

16. Laurer G. Rhombic 3D Condylar Fracture Plate: Threedimensional geometries for multilateral forces. KLS Martin 2013.

17. Sikora M, Sielski M, Stąpor A, Chlubek D. Use of the Delta plate for surgical treatment of patients with condylar fractures. J Craniomaxillofac Surg. 2016; 44(7):770-4.

18. Hou J, Chen L, Wang T, Jing W, Tang W, Long J, Tian W, Liu L. A new surgical approach to treat medial or low condylar fractures: the minor parotid anterior approach. Oral Surg Oral Med. Oral Pathol Oral Radiol. 2014; 117 : 283-8.

19. Croce A, Moretti A, Vitullo F, Castriotta A, Rosa de M, Citraro L. Transparotid approach for mandibular condylar neck and subcondylar fractures. Acta Otorhinolaryngol Ital. 2010; 30:303-9.

20. Ellis E 3rd, McFadden D, Simon P, Throckmorton G. Surgical complications with open treatment of mandibular condylar process fractures. J Oral Maxillofac Surg. 2000;58: 950-8.

21. Choi BH, Yi CK, Yoo JH. Clinical evaluation of 3 types of plate osteosynthesis for fixation of condylar neck fractures. J Oral Maxillofac Surg. 2001; 59:734-7.

22. Sandler NA. Endoscopic-assisted reduction and fixation of mandibular subcondylar fracture: report of a case. J Oral Maxillofac Surg 2001; 59:1479-82.

23. Zrounba H, Lutz JC, Zink S, Wilk A. Epidemiology and treatment outcome of surgically treated mandibular condyle fractures. A five years' retrospective study. J Craniomaxillofac Surg2014; 42:879-84.

24. Hidding J, Wolf R, Pingel D. Surgical versus non-surgical treatment of fractures of the articular process of the mandible. J Cranio-maxillofac Surg 1992; 20:345-7.
25. You HJ, Moon KC, Yoon ES, Lee BI, ParkSH. Clinical and radiological outcomes of transoral endoscope assisted treatment of mandibular condylar fractures. Int J Oral Maxillofac Surg.2016;45:284-91.

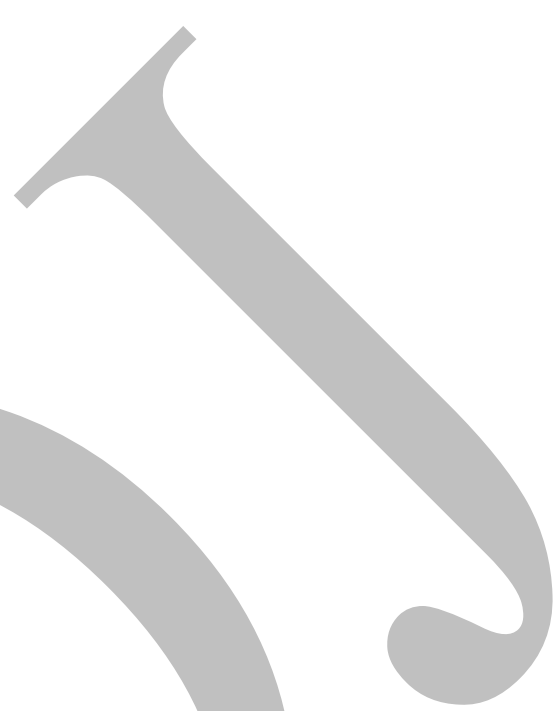

